\title{
NECROSE IDIOPÁTICA DO EPÍPLOO
}

\section{IDIOPATIC NECROSIS OF THE EPIPLOON}

\section{Antonio Carlos Valezi, TCBC-PR ${ }^{1}$ \\ Edivaldo Macedo de Brito, ACBC-PR ${ }^{2}$ \\ Eufânio Stefano Saquetti ${ }^{3}$}

\section{INTRODUÇÃO}

A necrose de epíploo é uma entidade incomum, que se apresenta com quadro clínico semelhante a outras doenças causadoras de dor abdominal ${ }^{1}$. Considerando que a maioria dos estudos sobre este assunto se concentra em relatos de casos isolados, e que os mesmos ainda apresentam uma incidência rara, o estudo desta entidade clínico-cirúrgica mantém sua importância.

\section{RELATO DO CASO}

Homem, 34 anos, chegou ao Serviço de Emergência com dor abdominal contínua, de início súbito, com 24 horas de evolução, localizada em flanco direito, referindo início na região periumbilical, acompanhada de parada de eliminação de gases e fezes. Sem história de trauma ou cirurgia prévia e ausência de queixas geniturinárias associadas.

Ao exame, o paciente apresentava-se afebril, com palpação dolorosa de quadrante inferior direito, descompressão brusca indolor e ruídos hidroaéreos diminuídos difusamente.

Exame radiológico abdominal mostrou-se inespecífico. Ultra-sonografia do abdome identificou, em fossa ilíaca direita, massa heterogênea com alças intestinais aderidas. Exames laboratoriais revelaram urinálise normal e leucocitose discreta $\left(10.200 / \mathrm{mm}^{3}\right)$, sem desvio.

O paciente foi submetido à laparoscopia, com o diagnóstico presuntivo de apendicite aguda onde evidenciouse epíploo aderido à parede abdominal periumbilical com aspecto necrótico, sem outras alterações na cavidade. Apêndice normal. Realizada dissecção com posterior ressecção do epíploo. Exame anatomopatológico da peça confirmou tecido adiposo com congestão vascular, focos de hemorragia e de necrose.

O paciente evoluiu sem intercorrências, com alta no segundo dia de pós-operatório.

\section{DISCUSSÃO}

Bush, em 1896, relatou o primeiro caso de necrose de epíploo atribuído a uma torção² . Johnson, em 1932, publicou o primeiro caso de infarto idiopático ${ }^{3}$. Desde então diversos autores têm distinguido dois tipos de infarto com e sem torção, onde se estabelecem diferenças na etiologia e patologia de ambas as entidades ${ }^{5}$.

A torção é resultado de um infarto segmentar ainda não totalmente esclarecido - congestão venosa, mudança súbita de posição do corpo, focos infecciosos ou inflamatórios e até mesmo malformação do epíploo, vem sendo responsabilizados como causa da torção ${ }^{4,5}$.

Os casos idiopáticos continuam sob investigação científica. Porém, sabe-se que existe uma trombose ou hemorragia que resulta na ruptura de pequenos vasos. Tipicamente, o infarto é triangular, onde o segmento de epíploo apresenta-se com uma área bem delimitada e normalmente envolve o epíploo inferior direito, provavelmente por se tratar de uma região mais rica em gordura e de maior mobilidade. Com o impedimento do retorno venoso, o epíploo distal torna-se congesto e edematoso, podendo ocorrer extravasamento de sangue ou fluido na cavidade, determinando irritação peritoneal . $\mathrm{O}$ tamanho da área infartada pode variar desde 2 até 20 centímetros ${ }^{5}$.

Independente da etiologia, trata-se de uma doença pouco freqüente, tendo sido publicados aproximadamente 200 casos na literatura mundial desde a descrição inicial ${ }^{4,5}$.

1. Professor Adjunto - Doutor do Departamento de Cirurgia do Centro de Ciências da Saúde da Universidade Estadual de Londrina.

2. Professor Adjunto - Mestre do Departamento de Cirurgia do Centro de Ciências da Saúde da Universidade Estadual de Londrina.

3. Residente do Departamento de Cirurgia do Centro de Ciências da Saúde da Universidade Estadual de Londrina.

Recebido em 19/07/2000

Aceito para publicação em 27/06/2001

Trabalho realizado no Serviço de Emergência do Hospital Universitário da Universidade Estadual de Londrina 
Estudos mostram uma relação homem mulher de 3:1. A obesidade e exercícios físicos vigorosos podem ser considerados fatores predisponentes ${ }^{4}$. Ocorrência em crianças e gestantes é extremamente rara ${ }^{1}$.

A apresentação clínica caracteriza-se por dor abdominal de início súbito, normalmente localizada em quadrante inferior direito e sem sintomas gastrintestinais associados, como náuseas e vômitos. Sinais de irritação peritoneal são freqüentes, e nos casos de torção, uma massa dolorida pode ser palpada. Dentro desta apresentação clínica, o diagnóstico de apendicite aguda normalmente é estabelecido $^{1,4,5}$. No entanto, há relatos de pacientes que tiveram o diagnóstico prévio de colecistite aguda ${ }^{4,5}$, torção de cisto de ovário, diverticulite colônica aguda, aneurisma de aorta abdominal, úlcera péptica perfurada e outros, até que se confirmasse o quadro de necrose de epíploo ${ }^{5}$.

Dentro do arsenal diagnóstico, o exame radiológico simples é inespecífico, e a ultra-sonografia, mais utiliza- do ${ }^{5}$, não é bom método para observação de doenças que envolvem o trato gastrintestinal. Karak, em 1998, relatou dois casos diagnosticados pela tomografia computadorizada, evidenciando o infarto omental propriamente dito ${ }^{4}$ .Todavia o diagnóstico definitivo desses quadros normalmente se faz por intervenção cirúrgica. Até o advento da laparoscopia, a laparotomia era o procedimento de escolha ${ }^{5}$.

Trata-se, de um quadro raro, manifestado por dor abdominal de início súbito, normalmente localizado em fossa ilíaca direita, freqüentemente confundido com apendicite aguda, e que a resolução diagnóstica e terapêutica, se faz pela via cirúrgica, onde a ressecção do omento doente é curativa em $100 \%$ dos casos.

Este doente, confirmando os dados da literatura, era homem, obeso, com quadro de dor em flanco e fossa ilíaca direita e descompressão brusca dolorosa. A preferência pela laparoscopia se deu pelo fato de não haver certeza do diagnóstico de apendicite aguda.

\begin{abstract}
The most common causes of acute abdominal pain are acute apendicites or cholecistites among several other causes, but uncommon ethiology should be remembered. The authors report a case of a 34 year-old man with necrosis of the epiploon that simulated an acute apendicites. The correct diagnosis and the treatment were done by laparoscopy.
\end{abstract}

Key Words: Epiploon necrosis; Abdominal pain.

\title{
REFERÊNCIAS
}

1. Berlin M. Omental infarction in pregnancy. New York State Journal of Medicine, 1989, 11:634-5.

2. Bush P. A case of haemorrhage into the greater omentum. Lancet, 1896, 286.

3. Johnson AH.The great omentum and omental thrombosis.Northwest Med, 1939,31:285-90.

4. Karak PK, Millmond SH, Neumann D. Omental infarction:Report of three cases and review of the literature. Abdominal Imaging, 1998, 23(1):96-8.
5. Mack P, Chekka OAM, Singh Sidhu D. Acute omental infarction - A report of six cases. Annals Academy of Medicine Singapure, 1989, 6:710-12.

Endereço para correspondência:

Antonio Carlos Valezi

Rua Santos, 777/1.302

86020-021 — Londrina-PR 